\title{
PEMBUATAN PETA KONSEP MEMANFAATKAN VISUALISASI GRAFIK PERSAMAAN KUADRAT BERBANTUAN GEOGEBRA
}

\author{
Tundung Memolo \\ SMPN 2 KALIBAWANG \\ Jl. Kalikarung, Kalibawang, Wonosobo, paktundungmemolo@gmail.com
}

\begin{abstract}
ABSTRAK
Pendekatan Realistic Mathematics Education (RME) meliputi dua konsep utama, yaitu matematisasi horisontal dan matematisasi vertikal. Matematisasi horisontal melibatkan ekspresi matematis dari masalah kehidupan nyata. Sedangkan matematisasi vertikal melibatkan ekspresi ulang matematika dengan penggunaan simbol. Dalam konteks ini, matematisasi horisontal menggunakan model, grafik dan diagram. Salah satu bentuk representasi dari grafik adalah penggunaan Geogebra. Geogebra adalah perangkat lunak matematika dinamis untuk sekolah yang menggabungkan geometri, aljabar, dan kalkulus. Kendala yang dihadapi siswa adalah mereka membutuhkan waktu yang lama di dalam membuat sketsa grafik persamaan kuadrat. Akibatnya, para siswa terhambat di dalam menganalisis bentuk kurva dalam beragam nilai. Oleh karenanya, perlu dibuat peta konsep yang dibangun dengan pemahaman siswa itu sendiri melalui pembelajaran dengan menggunakan Geogebra. Tujuan penelitian ini adalah untuk membuat peta konsep setelah melihat visualisasi beragam grafik persamaan kuadrat dengan bantuan Geogebra. Metode penelitian ini berdasarkan tujuannya termasuk penelitian dasar yang berguna membuktikan dan menjelaskan sebuah teori. Hasil penelitian menunjukkan bahwa grafik fungsi persamaan kuadrat dapat divisualisasi dengan jelas menggunakan Geogebra. Manipulasi nilai a,b, dan c dapat dilakukan pada Geogebra, yang selanjutnya Deskriminan (D) dapat dicari. Selanjutnya dapat dibuat peta konsep yang memvisualisasi hubungan antara nilai a,b,c, atau D dengan grafik persamaan kuadrat. Nilai a memvisualisasi keterbukaan grafik, apakah terbuka ke atas atau ke bawah. Nilai b terkait dengan nilai a yang memvisualisi sumbu simetri. Nilai $\mathrm{c}$ memvisualisasi perpotongan grafik dengan sumbu Y, sedangkan nilai D memvisualisasi perpotongan grafik dengan sumbu $\mathrm{X}$, apakah berpotongan ataukah tidak.
\end{abstract}

Kata Kunci : geogebra, grafik, peta konsep, visualisasi

\begin{abstract}
The Realistic Mathematics Education (RME) approach includes two main concepts, namely horizontal mathematics and vertical mathematization. Horizontal mathematization involves the mathematical expression of real-life problems. While vertical mathematization involves mathematical re-expression with the use of symbols. In this context, horizontal mathematization uses models, graphs and diagrams. One form of representation of the graph is the use of Geogebra. Geogebra is a dynamic mathematical software for schools that combines geometry, algebra, and calculus. Constraints faced by students is that they take a long time in sketching the graph of quadratic equations. As a result, students are hampered in analyzing the shape of the curve in varying values. Therefore, it is necessary to create a concept map built with the students' own understanding through learning by using Geogebra. The purpose of this study was to create a concept map after viewing the visualization of various graphs of quadratic equations with the help of Geogebra. This research method based on its purpose includes basic research that is useful to prove and explain a theory. The results showed that
\end{abstract}


the graph of the function of quadratic equations can be clearly visualized using Geogebra. The manipulation of values $a, b$, and c can be done on Geogebra, the next Deskriminan (D) can be searched. Furthermore, a concept map can be created that visualizes the relationship between a, b, c, or $\mathrm{D}$ values with a graph of quadratic equations. A value visualizes the openness of the graph, whether it is open up or down. The value of $b$ is related to the value of a which visualizes the symmetry axis. The value of $\mathrm{c}$ visualizes the intersection of the graph with the $\mathrm{Y}$ axis, whereas the $\mathrm{D}$ value visualizes the intersection of the graph with the $\mathrm{X}$ axis, whether intersected or not.

Keyword : geogebra, graphic, concept map, visualization

\section{Pendahuluan}

Manusia telah merancang dan terus mengembangkan matematika karena keharusan membuat perhitungan tertentu dalam kehidupan sehari-hari. Hans Freudenthal (dalam Aktumen, Horzum, \&Ceylan, 2013) menyarankan itu, secara historis, matematika menemukan asal usulnya dalam masalah kehidupan nyata. Aspek kehidupan nyata kemudian dibuat matematis dan matematika formalpun tercapai sesudahnya.

Hans Freudenthal telah menamai ini dengan Realistic Mathematics Education (RME). Pendekatan ini meliputi dua konsep utama, yaitu matematisasi horisontal dan matematisasi vertikal. Matematisasi horisontal melibatkan ekspresi matematis dari masalah kehidupan nyata. Sedangkan matematisasi vertikal melibatkan ekspresi ulang matematika dengan penggunaan simbol. Dalam konteks ini, matematisasi horisontal menggunakan model, grafik dan diagram. Salah satu bentuk representasi dari grafik adalah penggunaan Geogebra.

Menurut Hohenwarter, Judith \&Markus (2008) Geogebra adalah perangkat lunak matematika dinamis untuk sekolah yang menggabungkan geometri, aljabar, dan kalkulus. Geogebra adalah visualisasi geometri interaktif. Seseorang dapat melakukan konstruksi dengan titik, vektor, segmen, garis, dan bagian kerucut serta berfungsi saat mengubahnya secara dinamis setelahnya. Di sisi lain, persamaan dan koordinat bisa langsung masuk. Demikianlah, Geogebra memiliki kemampuan untuk menangani variabel untuk bilangan, vektor, dan titik.

Geogebra dapat juga menentukan fungsi derivatif (turunan) dan integral dan menawarkan perintah seperti akar atau vertex (titik puncak). Kedua pandangan ini merupakan ciri khas Geogebra: sebuah ekspresi dalam jendela aljabar sesuai dengan objek di jendela geometri dan sebaliknya. 
Dalam matematika sekolah (Roulet, Geoffrey \& Lazarus,Jill, 2013), keterwakilan ide matematika dan situasi pemodelan umumnya berbentuk numerik, geometris, grafis, representasi aljabar, bergambar, dan konkret, juga sebagai representasi menggunakan perangkat lunak dinamis. Siswa harus bisa berpindah dari satu representasi ke representasi yang lain, mengenali koneksi antara representasi, dan menggunakan representasi yang berbeda secara tepat dan sesuai yang dibutuhkan untuk memecahkan masalah.

Kendala yang dihadapi siswa adalah mereka membutuhkan waktu yang lama di dalam membuat sketsa grafik persamaan kuadrat. Akibatnya, para siswa terhambat di dalam menganalisis bentuk kurva dalam beragam nilai. Oleh karenanya, perlu dibuat peta konsep yang dibangun dengan pemahaman siswa itu sendiri melalui pembelajaran dengan menggunakan Geogebra.

Tujuan penelitian ini adalah untuk membuat peta konsep setelah melihat visualisasi beragam grafik persamaan kuadrat dengan bantuan Geogebra.

\section{Metode Penelitian}

Penelitian ini menggunakan metode penelitian berdasarkan tujuan yaitu basic research (penelitian dasar). Menurut Wibawa (2016) peneltian dasar adalah penelitian yang berusaha untuk menemukan, mengembangkan, ataupun mengevaluasi sebuah teori. Penelitian dasar (Schoenfeld, 2008) merupakan penelitian yang mendasarkan pada pengetahuan umum. Penelitian ini diterapkan dalam ilmu murni baik fisika, matematika, ataupun kimia. Penggunaan geogebra dalam penelitian ini sebagai alat bantu visualisasi beragam grafik persamaan kuadrat sehingga memudahkan membuat peta konsep melalui generalisasi.

\section{Hasil dan Pembahasan}

Menurut Kanginan (2004) bentuk persamaan kuadrat dapat ditulis dalam bentuk umum berikut : $a x^{2}+b x+c$ dengan $a, b, c \in R$, dan $a \neq 0$. Suatu bentuk kuadrat dapat difaktorkan dengan dua cara:
a. memfaktorkan dalam bentuk perkalian dua buah faktor linier
b. memfaktorkan dengan melengkapkan kuadrat sempurna 
Bilamana tidak bisa diselesaikan dengan cara tersebut, maka dapat diselesaikan dengan menggunakan rumus $a b c$. Jika suatu persamaan kuadrat $a x^{2}+b x+c=0, a \neq 0, \quad$ memiliki penyelesaian $\mathrm{x}$ real, penyelesaiannya diberikan oleh persamaan

$$
x_{1,2}=\frac{-b \pm \sqrt{b^{2}-4 a c}}{2 a}
$$

Pembuatan sketsa grafik persamaan kuadrat dapat dilakukan dengan mengikuti langkah - langkah sebagai berikut :

1. Faktorkan bentuk fungsi kuadrat untuk mencari titik potong dengan sumbu X

2. Menentukan titik potong dengan sumbu Y

3. Tentukan titik minimum $(x, y)$ atau maksimumnya

Gunakan rumus $x=\frac{-b}{2 a}$ dan $y=\frac{-D}{4 a}$

4. Tentukan persamaan sumbu simetrinya

5. Gambar grafik persamaan kuadrat dengan pedoman jika a > 0 maka kurva terbuka ke atas dan jika a $<0$ maka kurva terbuka ke bawah.

Berikut ini beberapa representasi grafik persamaan kuadrat dengan menggunakan bantuan geogebra :

1. Grafik 1

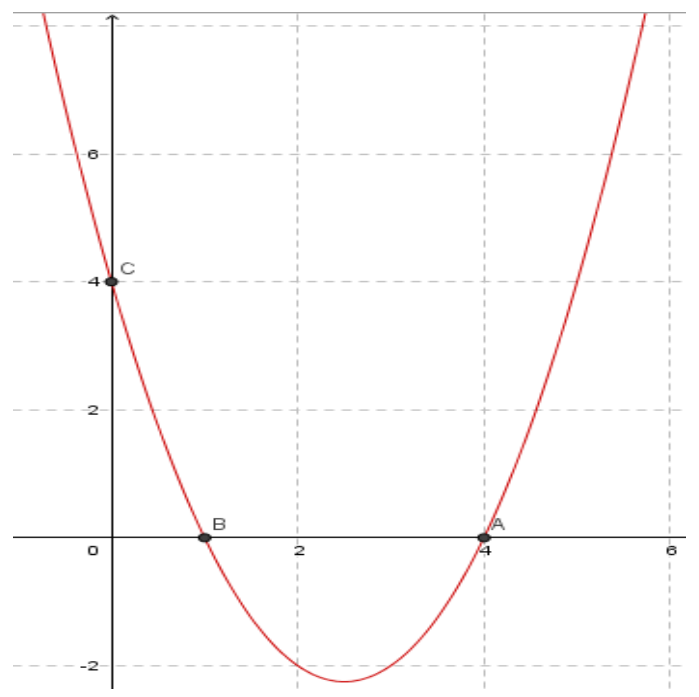

Gambar 1. Grafik $y=x^{2}-5 x+4$ Perhatikan grafik di atas, misalkan grafik fungsi kuadrat di atas adalah $y=a x^{2}+b x+c$, maka dari grafik di atas terlihat bahwa :

a. titik potong dengan sumbu $\mathrm{Y}$ adalah $(0,4)$, artinya nilai $\mathrm{c}=4$

b. titik potong dengan salah satu sumbu $\mathrm{X}$ adalah $\mathrm{A}(4,0)$ dan $\mathrm{B}(1,0)$, artinya penyebab grafik memiliki nilai ordinat 0 pada absis 4 dan absis 0 .

c. grafik terbuka ke atas, artinya a $>0$.

d. grafik berpotongan dengan sumbu-X, artinya deskriminan (D) $>0$.

Bagaimana persamaan grafik di atas ? Misalkan $\mathrm{y}=\mathrm{ax}^{2}+\mathrm{bx}+\mathrm{c}$, dengan $\mathrm{c}=4$, maka $\mathrm{y}=\mathrm{ax}^{2}+\mathrm{bx}+4$; dengan $\mathrm{A}(4,0)$, didapatkan $0=\mathrm{a} \cdot 4^{2}+\mathrm{b}(4)+4$. Dengan demikian $0=16 a+4 b+4 ; 16 a+4 b=-4$

$$
4 a+b=-1 \ldots .(1)
$$

Dengan $\mathrm{B}(1,0)$, maka $0=\mathrm{a}(1)^{2}+\mathrm{b}(1)+4$ sehingga $0=a+b+4$ didapatkan 


$$
a+b=-4 \ldots(2)
$$

Dengan mengeliminasi persamaan (1) dan (2) didapatkan $\mathrm{a}=1, \mathrm{~b}=-5$. Dengan demikian persamaan menjadi $\mathrm{y}=\mathrm{x}^{2}-5 \mathrm{x}+4$. Terlihat bahwa a $>0$ dan grafik terbuka ke atas. Memperhatikan nilai $\mathrm{D}=\mathrm{b}^{2}-4 \mathrm{ac}=(-$ $5)^{2}-4.1 .4=25-16=9$, terlihat bahwa D > 0 dan grafik berpotongan pada sumbu $\mathrm{X}$.

\section{Grafik 2}

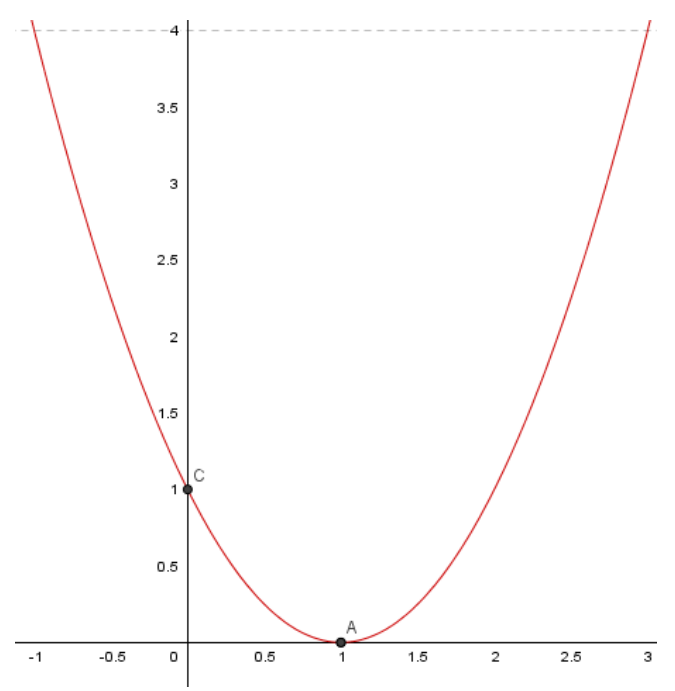

Gambar 2. Grafik $y=x^{2}-2 x+1$

Perhatikan grafik di atas, misalkan grafik fungsi kuadrat di atas adalah $\mathrm{y}=\mathrm{ax}^{2}+\mathrm{bx}+\mathrm{c}$, maka dari grafik di atas terlihat bahwa :

a. titik potong dengan sumbu $\mathrm{Y}$ adalah $(0,1)$, artinya nilai $\mathrm{c}=1$

b. titik potong dengan salah satu sumbu $\mathrm{X}$ adalah $\mathrm{A}(1,0)$, artinya penyebab grafik memiliki nilai ordinat 0 pada absis 1 . c. titik minimum grafik fungsi tersebut adalah $(1,0)$

d. grafik terbuka ke atas, artinya a $>0$.

e. grafik berpotongan dengan sumbu-X, artinya deskriminan (D) $>0$.

f. sumbu simetri pada garis $\mathrm{x}=1$

Bagaimana persamaan grafik di atas ? Misalkan $\mathrm{y}=\mathrm{ax}^{2}+\mathrm{bx}+\mathrm{c}$, dengan $\mathrm{c}=1$, maka $y=a x^{2}+b x+1$; dengan $\mathrm{A}(1,0)$, sehingga $0=a \cdot 1^{2}+b(1)+1$, dengan demikian $0=\mathrm{a}+\mathrm{b}+1$ didapatkan

$$
a+b=-1
$$

Karena titik minumum pada $(1,0)$, maka berdasar rumus nilai absis pada titik minimum adalah $-\mathrm{b} / 2 \mathrm{a}$, didapatkan $\frac{-b}{2 a}=1$ Sehingga $-b=2 a$ oleh karena itu

$$
b=-2 a \ldots \text { (4) }
$$

Substitusi persm (4) ke persm (3) $\mathrm{a}+(-2 \mathrm{a})=-1 ; \mathrm{a}-2 \mathrm{a}=-1 ;-\mathrm{a}=-1$ didapatkan $\mathrm{a}=1$. Karena $\mathrm{a}=1$, maka $\mathrm{b}=-2(1)=-2$ dengan demikian $y=x^{2}-2 x+1$, terlihat bahwa a $>0$ dan grafik terbuka ke atas.

Memperhatikan $\mathrm{D}=\mathrm{b}^{2}-4 \mathrm{ac}=(-2)^{2}-4.1 .1$ $=4-4=0$, terlihat bahwa $\mathrm{D}=0$ maka grafik berpotongan pada sumbu $\mathrm{X}$ di satu titik.

\section{Grafik 3}




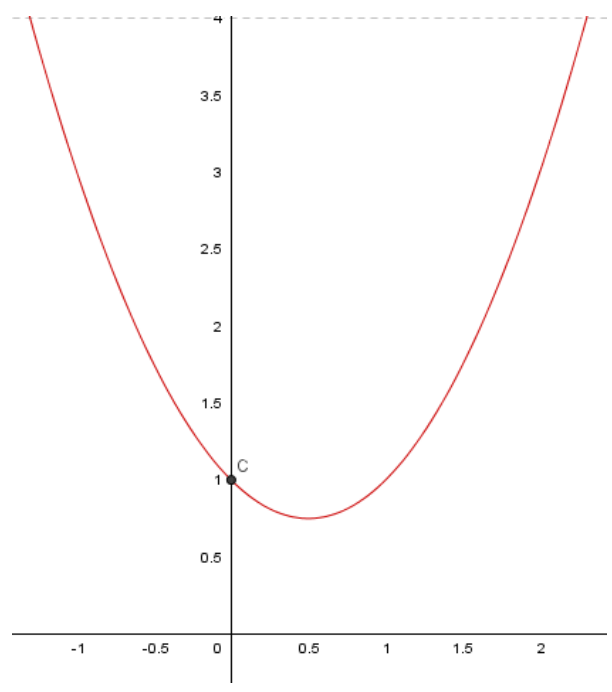

Gambar 3. Grafik $y=x^{2}-x+1$

Grafik fungsi kuadrat di atas adalah $y=x^{2}-$ $\mathrm{x}+1$

Bisa diambil informasi bahwa titik potong dengan sumbu Y adalah $(0,1)$.

Absis yang menyebabkan grafik di atas bernilai minimum dicari dengan

$x=-\frac{b}{2 a}=-\frac{-1}{2(1)}=-\frac{1}{2}$

Grafik terbuka ke atas karena a $>0$. Nilai $\operatorname{deskriman}(\mathrm{D})=\mathrm{b}^{2}-4 \mathrm{ac}=(-1)^{2}-4 \cdot 1.1=1$ $-4=-3$, terlihat bahwa $\mathrm{D}<0$ maka grafik tidak berpotongan pada sumbu $X$.

4. Grafik 4

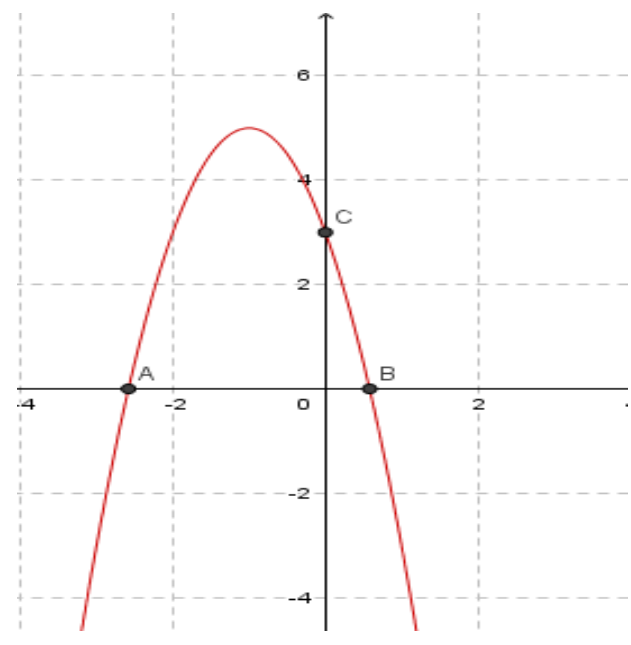

Gambar 4. Grafik $y=-2 x^{2}-4 x+3$

Persamaan grafik di atas adalah $y=-2 x^{2}-4 x$ $+3$

a. Terlihat $\mathrm{a}<0$, saat $\mathrm{a}<0$ maka grafik terbuka ke bawah.

b. Terlihat bahwa sumbu simetri pada absis negatif, oleh karenanya $b<0$

c. c $>0$, grafik berpotongan di sumbu y dengan ordinat positif.

d. Deskriminan (D) $=b^{2}-4 a c$ oleh karenanya $(-4)^{2}-4 \cdot(-2) \cdot 3=16+24=40>$ 0 ; karena $\mathrm{D}>0$, maka berpotongan dengan sumbu $\mathrm{X}$ di dua titik. 


\section{Grafik 5}

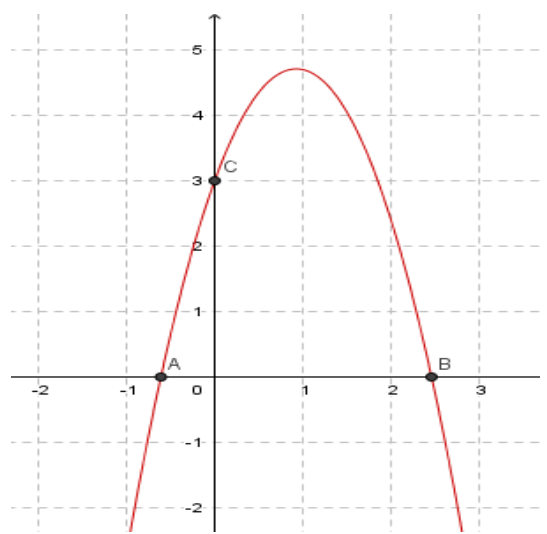

Gambar 5. Grafik Terbuka ke Bawah 1

Grafik di atas dapat dicari $\mathrm{a}<0, \mathrm{~b}>0$, c $>0, \mathrm{D}>0$.

6. Grafik 6

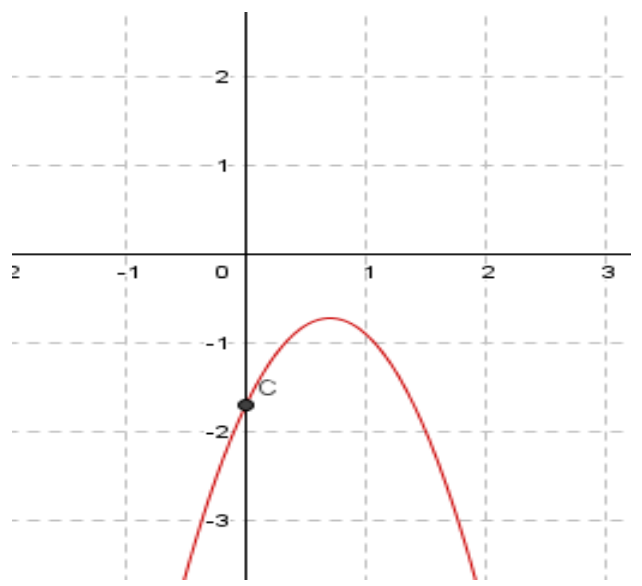

Gambar 6. Grafik Terbuka ke Bawah 2

Grafik di atas dapat dicari $\mathrm{a}<0 ; \mathrm{b}>0 ; \mathrm{c}$ $<0 ; \mathrm{D}<0$

\section{Grafik 7}

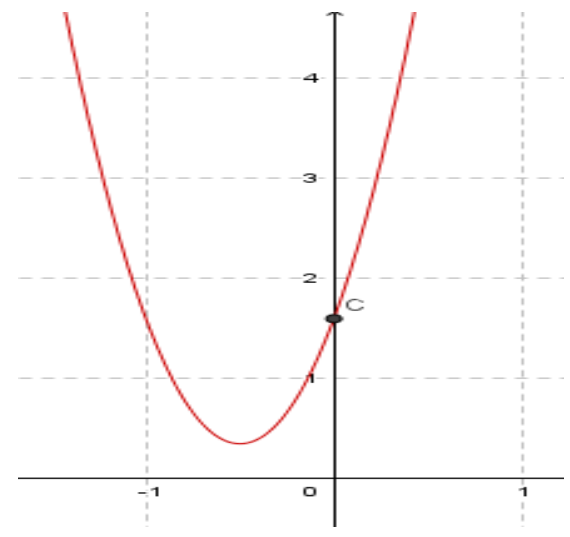

Gambar 7. Grafik Terbuka ke Atas

Terlihat grafik :

$a>0, b>0, c>0, D<0$

a > 0 karena kurva terbuka ke atas

b > 0 karena sumbu simetri pada absis negatif

c $>0$, karena titik potong grafik pada sumbu Y positif

$\mathrm{D}<0$, karena kurva tidak berpotongan dengan sumbu $X$

Dari pemaparan representasi di atas dapat dianalisis seperti dalam tabel berikut ini :

Tabel 1. Analisis Grafik

\begin{tabular}{|c|c|c|c|c|c|}
\hline No & $\mathbf{A}$ & b & c & D & Penjelasan \\
\hline 1 & + & + & & & $\begin{array}{l}\text { terbuka ke atas, sumbu } \\
\text { simetri pada absis negatif }\end{array}$ \\
\hline 2 & + & - & & & $\begin{array}{l}\text { terbuka ke atas, sumbu } \\
\text { simetri pada absis positif }\end{array}$ \\
\hline 3 & - & + & & & $\begin{array}{l}\text { terbuka ke bawah, sumbu } \\
\text { simetri pada absis positif }\end{array}$ \\
\hline 4 & - & - & & & $\begin{array}{l}\text { terbuka ke bawah, sumbu } \\
\text { simetri pada absis negatif }\end{array}$ \\
\hline 5 & & & + & & $\begin{array}{l}\text { titik potong grafik pada } \\
\text { sumbu Y positif }\end{array}$ \\
\hline 6 & & & - & & $\begin{array}{l}\text { titik potong grafik pada } \\
\text { sumbu Y negatif }\end{array}$ \\
\hline 7 & & & & + & memotong sumbu Y positif \\
\hline 8 & & & & - & $\begin{array}{l}\text { memotong sumbu } \quad Y \\
\text { negatif }\end{array}$ \\
\hline
\end{tabular}


Peta konsep (Baralos, 2012) adalah alat yang sangat berguna untuk menekankan koneksi matematika secara eksplisit sebagai representasi visual dari sebuah struktur pengetahuan individu pada topik tertentu. Representasi ini berbentuk simpul yang menggambarkan konsep matematika dan link (garis atau busur) yang mewakili hubungan di antara mereka. Menurut Martin (dalam Baralos, 2012) peta konsep adalah representasi dua dimensi kognitif struktur yang menunjukkan hierarki dan keterkaitan konsep.

Peta konsep adalah alat visual untuk mewakili hubungan pengetahuan (Mwakapenda, 2003). Dalam peta konsep garis ditarik antara pasangan konsep untuk menunjukkan hubungan antar konsep. Menghubungkan kata-kata di garis menunjukkan bagaimana caranya pasangan konsep saling terkait Dengan cara ini, proposisi menunjukkan hubungan tertentu antar konsep bisa dibedakan. Pemetaan konsep sering digunakan sebagai alat pedagogis untuk membantu siswa "belajar lebih bermakna" dan membentuk "konseptual pemahaman tentang subjek ".
Menurut Marinkovic (2015), peta konsep memiliki struktur hirarkis. Pemetaan adalah proses kreatif mengorganisir konten dan bisa digunakan dalam perencanaan pelajaran, pembelajaran, kerja kelompok dan individu, pengembangan kemampuan literasi matematika, serta membina pemikiran matematis Pemetaan konseptual dapat dengan mudah diterapkan pada mata pelajaran sekolah dan juga kehidupan seharihari. Begitu diterima, membuat peta konsep menjadi cara belajar yang sukses.

Hasil penelitian Marinkovic (2015) menunjukkan bahwa pembuatan peta konsep cocok untuk pengajaran dan juga untuk pembelajaran, memberikan pembelajaran yang masuk akal dan bermakna, sehingga semua siswa aktif, meskipun mereka memiliki pengetahuan sebelumnya yang berbeda. Manfaat lain yang diperoleh bagi siswa adalah mengembangkan literasi matematika, memperluas pengetahuan, mengevaluasi proses pembelajaran, menghubungkan antara pengetahuan yang baru dengan sebelumnya, serta dapat diterapkan dalam pembelajaran materi yang lain. 
Keuntungan menggunakan peta konsep adalah adanya potensi untuk membuat disiplin ilmu lebih terlihat jelas dan tersampainya gagasan yang tidak mudah bila dituangkan ke dalam kata-kata. Makna konsep dibangun dengan menentukan hubungan antar konsep (Mwakapenda,2003).

Berdasarkan pemaparan pada tabel 1, dapat dibuat peta konsep analisis grafik persamaan kuadrat berikut :

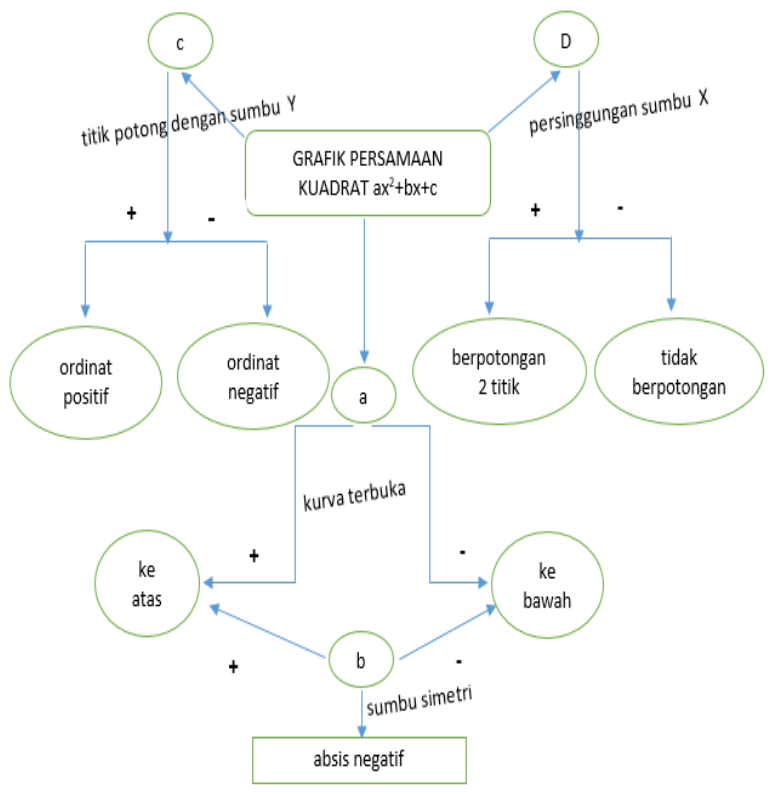

Gambar 8. Peta Konsep Grafik Persamaan

Kuadrat

\section{Kesimpulan}

Geogebra adalah perangkat lunak matematika dinamis untuk sekolah yang menggabungkan geometri, aljabar, dan kalkulus. Geogebra adalah bentuk visualisasi geometri interaktif. Ciri khas Geogebra adalah sebuah ekspresi dalam jendela aljabar sesuai dengan objek di jendela geometri dan sebaliknya.

Grafik fungsi persamaan kuadrat dapat divisualisasi dengan jelas menggunakan Geogebra. Manipulasi nilai a,b, dan c dapat dilakukan pada Geogebra, yang selanjutnya Deskriminan (D) dapat dicari.

Selanjutnya dapat dibuat peta konsep yang memvisualisasi hubungan antara nilai a,b,c, atau D dengan grafik persamaan kuadrat. Nilai a memvisualisasi keterbukaan grafik, apakah terbuka ke atas atau ke bawah. Nilai b terkait dengan nilai a yang memvisualisi sumbu simetri. Nilai c memvisualisasi perpotongan grafik dengan sumbu Y, sedangkan nilai D memvisualisasi perpotongan grafik dengan sumbu X, apakah berpotongan ataukah tidak.

\section{Ucapan Terimakasih}

Kami mengucapkan terimakasih kepada SEAMEO QITEP in Mathematics yang memfasilitasi pembelajaran Geogebra 
bersama Prof. Allan Leslie White, sehingga penelitian ini dapat terselesaikan dengan baik.

\section{Pustaka}

Aktumen, Horzum, \&Ceylan, 2013, Modeling and Visualization Process of the Curve of Pen Point by Geogebra, Jurnal :European Journal of Contemporary Education, vol(4), No 2

Baralos, George. 2012, Concept Mapping As Evaluation Tool In Mathematics. Jurnal. [online]. Tersedia di http://users.math.uoc.gr/ ictm2/Proce edings/pap451.pdf . Diakses tanggal 10 November 2017

Hohenwarter, Judith \& Markus. 2008,Introduction to Geogebra, [Online], Tersedia di http://math.arizona.edu/ vbohme/Ge ogebra/introtoGeoGebra.pdf, Diakses tanggal 9 November 2017. USA : NSF Math and Science

Kanginan, Martin. 2004, Matematika untuk SMU Kelas I, Bandung: Grafindo Media Pratama

Marinkovic, Zorica. 2015, Concept Maps in Math Teaching, Jurnal, [online]. Tersedia http://elib.mi.sanu.ac.rs/files/journals/ vm/57/vmn57p6-8.pdf, Diakses tanggal 10 November 2017

Mwakapenda, Willy. 2003, Concept Mapping and Context in Mathematics Education, Jurnal, Proceedings of the International Conference The Decidable and the Undecidable in Mathematics Education Brno, Czech Republic
Roulet, Geoffrey \& Lazarus, Jill. 2013, Linking Representations Using Geogebra, Jurnal, [online], Tersedia di

http://www.oame.on.ca/main/files/ga zettefiles/SelectedGazArt3411.pdf , Diakses tanggal 9 November 2017

Schoenfeld, Alan. 2008, Research methods in (mathematics) education, Artikel, [online]. Tersedia di https://gse.berkeley.edu/sites/default/ files/users/alan-h.schoenfeld/Schoenfeld_2008\%202nd $\% 20$ edn\%20int1\%20HBK.pdf, Diakses tanggal 1 Desember 2017 Wibawa, Basuki. 2016, Metode Peneltian Pendidikan, Tangerang Selatan : Universitas Terbuka 